\title{
Superposición de síndrome de Stevens Johnson/necrólisis epidérmica tóxica inducida por alopurinol
}

\author{
Allopurinol-induced Stevens-Johnson Syndrome/Toxic \\ Epidermal Necrolysis overlap syndrome
}

\section{CASE REPORT}

A 45-year-old Caucasian female was admitted to the Emergency Department with a diffuse maculo-papular erythematous and pruritic rash that developed over the last four days. In addition, she developed oral mucocutaneous painful hemorrhagic blisters and hemorrhagic crustations over the eyelids. She was medicated with allopurinol $300 \mathrm{mg}$ once a day for the first time about 10 days ago for asymptomatic hyperuricemia. About three days prior to presentation she became feeling photophobia, conjunctival itching, pain on swallowing, myalgias and fever. She had no prior history of a similar reaction or allergies. Upon examination, she was febrile and there were widespread, irregularly shaped erythematous and purpuric macules with blistering on more than $20 \%$ of the body surface area (BSA), including palms and soles and mucous membrane of mouth, anal canal and vagina. Nikolsky's sign was positive. Laboratory evaluation had mild leukocytosis without other relevant changes. A skin biopsy revealed keratinocyte necrosis of full-thickness of the epidermis with dermo-epidermal detachment and a scant, perivascular and inflammatory infiltrate of mononuclear cells in the superficial dermis (Image 1). The temporal association of allopurinol use and subsequent rash in addition of histologic and clinical findings suggested the diagnosis of allopurinol-Induced StevensJohnson Syndrome / Toxic Epidermal Necrolysis (SJS / TEN) overlap syndrome.

As per the Naranjo Adverse Drug Reaction Probability Scale, the score of 5 indicated a probable adverse drug reaction. Allopurinol was withdrawn immediately. Patient was monitored closely in an isolation room with nutritional and intravenous fluid therapy, oral hygiene, analgesia and daily observation by Ophthalmology. Dressings, topical antibacterial agents and emollients were used to cover cleansed wounds. Despite controversial, corticosteroid therapy was initiated with gradual diminished and healed up of lesions in about 20 days (Image 2). SJS and TEN are rare but potentially life-threatening and severe mucocutaneous reactions, characterized by extensive necrosis and detachment of the epidermis ${ }^{1}$. SJS/TEN overlap described patients with skin detachment of 10\%-30\% of BSA. Medications are the leading trigger of SJS/TEN and allopurinol is the drug most commonly associated². Diagnosis is clinical and confirmed with skin biopsy. Identification and removal of the precipitating agents should be done as early as possible and aggressive supportive measures should be taken to avoid mortality and morbidity $^{3}$. Patients must not be exposed to the trigger drug, avoid sunlight during healing and moisturize their skin.

\section{REFERENCES}

1. Stern RS, Divito SJ. Stevens-Johnson Syndrome and Toxic Epidermal Necrolysis: Associations, Outcomes, and Pathobiology-Thirty Years of Progress but Still Much to Be Done. J Invest Dermatol. 2017;137(5):1004-1008.
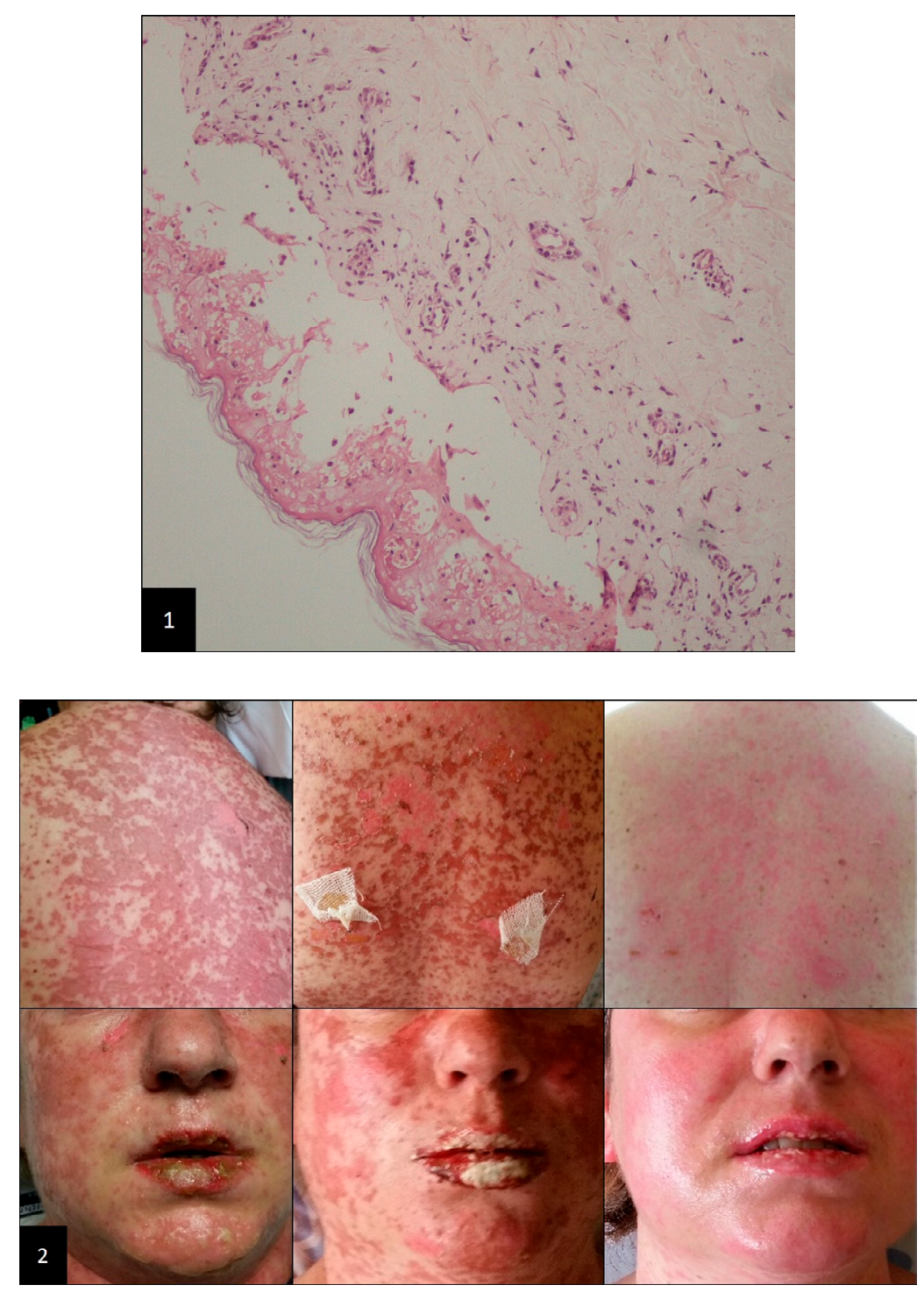

2. Halevy S, Ghislain PD, Mockenhaupt M, et al. Allopurinol is the most common cause of Stevens-Johnson syndrome and toxic epidermal necrolysis in Europe and Israel. J Am Acad Dermatol. 2008;58(1):25-32.

3. Gupta SS, Sabharwal N, Patti R, Kupfer Y. Allopurinol-Induced Stevens-Johnson Syndrome. Am J Med Sci. 2019;357(4):348-351.

Palabras clave: alopurinol, reacciones cutáneas adversas graves, síndrome de Stevens-Johnson, necrolisis epidérmica tóxica.

Keywords: Allopurinol, Severe cutaneous adverse reactions, Stevens-Johnson Syndrome, Toxic Epidermal Necrolysis.

\section{Paulo Almeida, Joel Pinto}

Serviço de Medicina Interna. Baixo Vouga Hospital Center

Correspondencia: pauloricardo.salmeida@gmail.com

Cómo citar este artículo: Almeida P, Pinto J

Superposición de síndrome de Stevens Johnson/necrólisis epidérmica tóxica inducida por alopurinol. Galicia Clin 2021; 82-1: 57

Recibido: 18/9/2019; Aceptado: 7/11/2019 // https://doi.org/10.22546/60/2088 